\title{
Behaviors of Polypyrrole Soft Actuators in LiTFSI or NaCl Electrolyte Solutions Containing Methanol
}

\author{
Tetsuya Kadoyama, Jun Yamasaki, Futo Tsumuji, Satoshi Takamiya, Shou Ogihara, \\ Daiki Hoshino, Yasushiro Nishioka* \\ Department of Precision Machinery, College of Science \& Technology, Nihon University, Chiba, Japan \\ Email: ${ }^{*}$ nishioka@eme.cst.nihon-u.ac.jp
}

Received June 18, 2013; revised July 18, 2013; accepted August 18, 2013

Copyright (C) 2013 Tetsuya Kadoyama et al. This is an open access article distributed under the Creative Commons Attribution License, which permits unrestricted use, distribution, and reproduction in any medium, provided the original work is properly cited.

\begin{abstract}
Organic soft linear actuators were fabricated using galvanostatic electropolymerization of the polypyrrole (PPy) thin film using a methyl benzoate electrolyte solution of N,N-Diethyl-N-methyl-N-(2-methoxyethyl) ammonium bis (trifluoromethanesulfonyl) imide. The electrochemical deformation behaviors of the PPy actuators were investigated in aqueous solutions of an electrolyte, lithium bis (trifluoromethanesulphonyl) imide (LiTFSI) or sodium chloride ( $\mathrm{NaCl}$ ), containing different concentrations of methanol. The actuating strain of approximately $9 \%$ was achieved when the actuator was driven by a potential between -1 and $1 \mathrm{~V}$ with the potential sweep rate of $10 \mathrm{mV} / \mathrm{s}$ corresponding to 0.0025 $\mathrm{Hz}$ in the LiTFSI electrolyte containing $40 \%$ to $50 \%$ of methanol under a load stress of $0.3 \mathrm{MPa}$. However, the PPy actuator could not catch up with the higher frequency. On the other hand, the PPy actuator caught up with the potential sweep up to $0.1 \mathrm{~Hz}$ in the $\mathrm{NaCl}$ solutions with a methanol concentration between $40 \%$ and $60 \%$ with the expense of the actuating strain to approximately $1 \%$.
\end{abstract}

Keywords: Soft Actuator; Polypyrrole; LiTFSI; $\mathrm{NaCl}$

\section{Introduction}

Organic soft linear actuators made of conducting polymers such as polypyrrole (PPy) films are of special interest for application in microelectromechanical systems (MEMS) because they generate large electrochemical stress between 3 and $5 \mathrm{MPa}$ and large strain [1-8]. Their electrochemical strains (actuating strain) were between $1 \%$ and $3 \%$. Recently, it has been reported that some PPy actuators exhibited actuating strains of more than $10 \%$ [9-14], and that some of those even achieved actuating strains of up to $40 \%$ [14]. The improved actuating strain has been mostly achieved using an electrolyte of tetra-nbutylammonium bis (trifluoromethansulfonyl) imide (TBATFSI) during PPy electropolymerization. These actuators generally function under a low potential voltage range less than $1 \mathrm{~V}$.

In the research of PPy actuators, not only larger electrochemical strain and stress but their operation speed is another important issue, and a PPy bending actuator was reported to operate at the frequency up to $90 \mathrm{~Hz}$ [15]. However, the force generated by the bending actuator was much smaller compared to the PPy linear actuators

${ }^{*}$ Corresponding author.
$[16,17]$. Similar PPy linear actuators were also reported to operate with at the frequency of $30 \mathrm{~Hz}[18,19]$. On the other hand, the performance of PPy actuators were reported to strongly dependent on the different kind of cations in the electrolyte solutions during actuation [20,21]. Kaneto et al. made systematic researches using different kinds of electrolytes such $\mathrm{LiCl}, \mathrm{NaCl}$, etc. for [22-24]. Hara et al. also reported that their TFSI-doped porous PPy films exhibited increased actuating strains when their aqueous lithium bis (trifluoromethansulfonyl)imide (LiTFSI) electrolyte solutions contained propylene carbonate [25]. They attributed those effects to the swelling of the PPy film caused by the penetration of propylene carbonate. The swelled PPy film could more easily pass TFSI anions. Hoshino et al. also found that the PPy films showed notable increase of actuating strains when they were functioned in LiTFSI solutions containing 2-propanol [26] or methanol [27]. However, the PPy actuators in the electrolyte solutions showed notable electrochemical creep after repeated actuation processes.

In this paper, we report on increased actuating strain of PPy actuators but with minimal increase of electrochemical creep in a LiTFSI electrolyte solution contain- 
ing optimized amounts of methanol. Moreover, we focus on the influences of different ions in the electrolyte solutions containing LiTFSI and $\mathrm{NaCl}$ during operation.

\section{Experiments}

The polymerization of PPy films was carried out using a computer-controlled potentio-galvanostat. A counter electrode (Ti), a reference electrode $(\mathrm{Ag} / \mathrm{AgCl})$, and a working electrode (Ti) were immersed into methyl benzoate solutions of $0.25 \mathrm{M}$ pyrrole and $0.2 \mathrm{M} \mathrm{N}, \mathrm{N}$-diethyl-Nmethyl-N-(2-methoxyethyl) ammonium bis (trifluoromethanesulfonyl) imide, and the potential voltage was controlled to keep a constant current of $0.2 \mathrm{~mA} / \mathrm{cm}^{2}$ for 4 $\mathrm{h}$ at $20^{\circ} \mathrm{C}$ between the counter electrode and the working electrode. These chemicals were purchased from SigmaAldrich Inc.

The PPy actuator was used as the working electrode in the $1 \mathrm{M}$ LiTFSI aqueous electrolyte solutions or in the 1 $\mathrm{M} \mathrm{NaCl}$ aqueous solutions with different methanol concentrations of $0 \%-100 \%$. The PPy actuator exhibited expansion and contraction motions under the alternating potential with the triangular wave shape applied between the PPy actuator and the counter electrode. The peak values of the potential voltage were -1 and $+1 \mathrm{~V}$, and the potential sweep rates were $10-400 \mathrm{mV} / \mathrm{s}$ that correspond to the frequencies between 0.0025 and $1 \mathrm{~Hz}$. The extension and contraction of the PPy actuator was measured by monitoring the displacement of the weight position using a laser displacement sensor as described in the previous publications [26-29]. A load stress of $0.3 \mathrm{MPa}$ was applied on the PPy actuator.

\section{Results and Discussion}

Figure 1 shows a typical measurement result for the relationship between the measured strain and time during repeated actuations at $0.0025 \mathrm{~Hz}$. This measurement was performed in the LiTFSI electrolyte solution containing $40 \%$ of methanol. The averaged strain continuously shifts to the positive strain direction due to electrochemical creep. Here, the electrochemical strain is defined as the change of the averaged strain as shown the dotted line in Figure 1. The difference between the peak values and the bottom values of the strain is defined as the actuating strain as indicated by the arrow in Figure 1.

Figures 2(a) and (b) show the comparison of the strain as a function of time under the repeated potential voltage change for actuators that were functioned in the LiTFSI solutions containing various concentrations of methanol. The actuators in the electrolyte solution with $20 \%$ and $80 \%$ methanol exhibited increased actuating strain compared to that in the electrolyte solution without methanol, and the actuating strains stayed at the similar level after 10 cycles of actuations as shown in Figure 2(a).

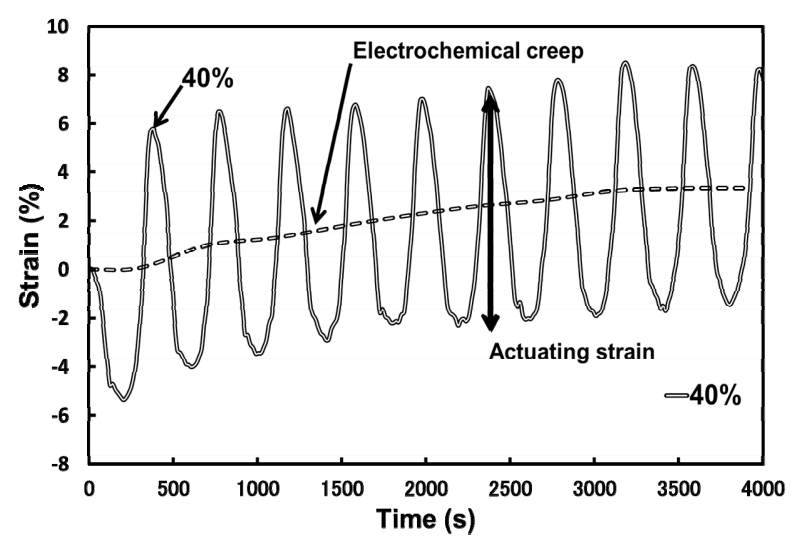

Figure 1. Relationship between strain and time for PPy actuator in LiTFSI electrolyte solution containing $40 \%$ methanol during electrochemical actuations at $0.0025 \mathrm{~Hz}$.

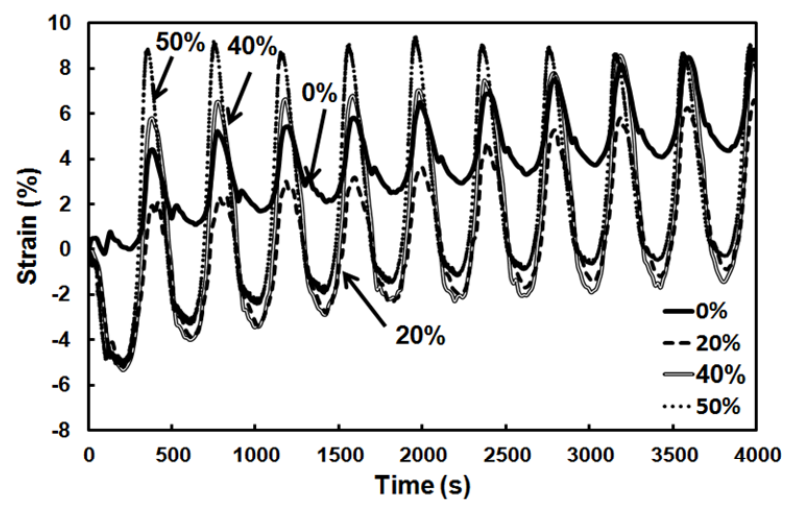

(a)

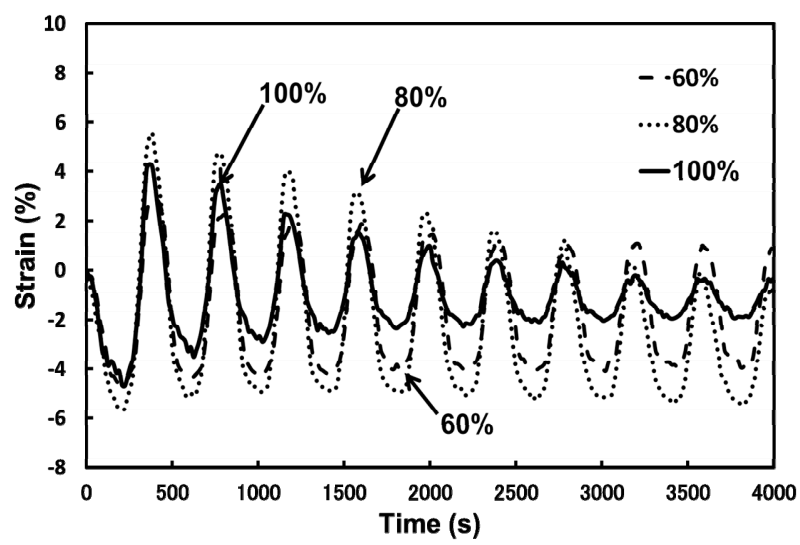

(b)

Figure 2. Relationship between strain and time during electrochemical actuations of PPy actuators in LiTFSI electrolyte solutions with different methanol concentrations at $0.0025 \mathrm{~Hz}$.

The electrochemical creep (continuous back ground change) gradually increased and approached to approximately $4 \%$. On the other hand, when the methanol concentration was increased from $60 \%$ to $100 \%$, the actuating strains of these actuators rapidly decreased after the 
repeated actuations as shown in Figure 2(b). On the other hand, the electrochemical creep seemed to be significantly smaller.

Figure 3 shows the relationships between the actuating strain and the methanol concentration after 10 cycles of actuations. The actuating strain showed the maximum value of $9 \%$ for the actuators functioned in the electrolyte solutions containing $40 \%$ or $50 \%$ of methanol. The actuating strain for the actuators functioned in the electrolyte solutions containing more than $60 \%$ of methanol exhibited rapid decreases.

Figure 4 shows the relationship between the electrochemical creep and the methanol concentration, and the electrochemical creep continuously decreased as a function of the methanol above $40 \%$.

Figures 5(a) and (b) compares the corresponding cyclic voltammograms of the PPy actuators functioned in the electrolyte solutions containing various concentrations of methanol. The current in the positive potential voltage range corresponds to the motion of large $\mathrm{TFSI}^{-}$ anions, and the current in the negative potential voltage range corresponds to the motion of small sized $\mathrm{Li}^{+}$ cations. Thus, a large volume change occurs in the positive potential voltage range. The largest hysteresis of the PPy actuator driven in the electrolyte solution with methanol implicates the enhancement of the TFSI ionic motions into or outwards the PPy actuator. The largest current with a large hysteresis occurred for the actuator functioned in the electrolyte solution containing $40 \%$ methanol, and the hysteresis curves continuously decreased as the methanol concentration increased above $60 \%$. This may explain the decreased actuating strain above the methanol concentration of $60 \%$.

However, consistent explanations for these behaviors of the PPy actuators functioned in the LiTFSI solutions containing various concentration of methanol have not been obtained. Table 1 compares the surface tension and viscosity of pure water and methanol at $20^{\circ} \mathrm{C}$. The data

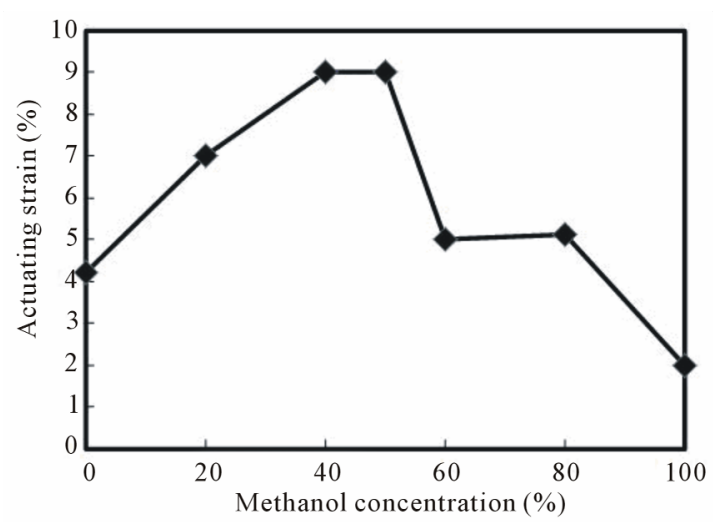

Figure 3. Change of actuating strain of PPy actuators in LiTFSI electrolyte solutions with different methanol concentrations as measured at $0.0025 \mathrm{~Hz}$.

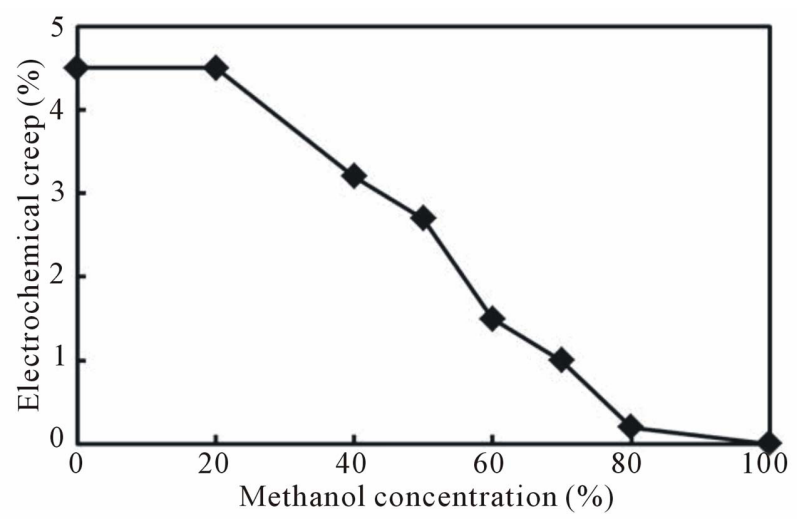

Figure 4. Change of electrochemical creep of PPy actuators in LiTFSI electrolyte solutions with different methanol concentrations as measured at $0.0025 \mathrm{~Hz}$.

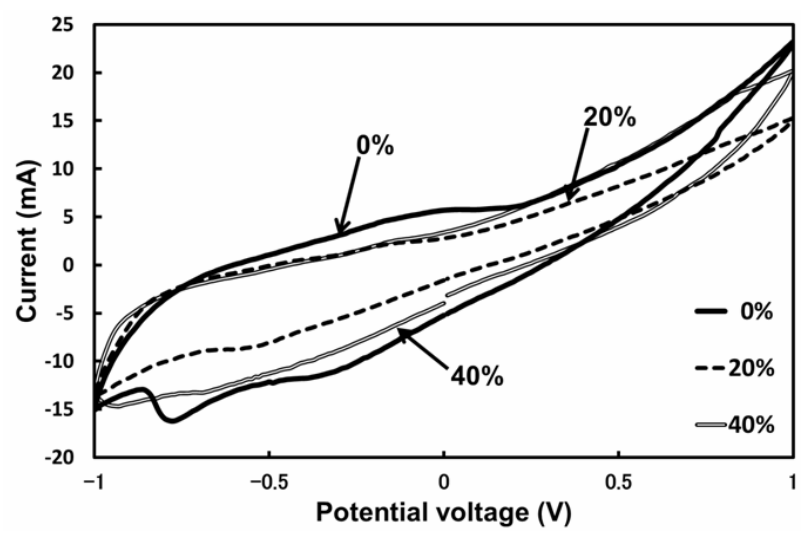

(a)

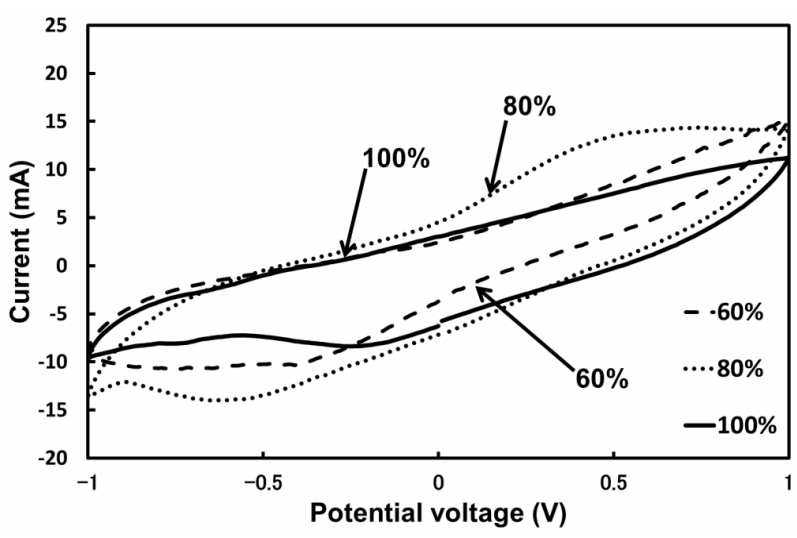

(b)

Figure 5. Cyclic voltammograms of the PPy actuators functioned in LiTFSI electrolyte solutions with different methanol concentrations.

Table 1. Comparison of surface tension and viscocity.

\begin{tabular}{ccc}
\hline & Surface tension $(\mathrm{dyn} / \mathrm{cm})$ & Viscosity $(\mathrm{mPa} \cdot \mathrm{s})$ \\
\hline Water & 72.8 & 1.01 \\
Methanol & 22.6 & 0.59 \\
\hline
\end{tabular}


were taken from the web page of the National Institute of Standards and Technology (NIST).

The surface tensions of methanol are $22.6 \mathrm{dyn} / \mathrm{cm}$, which are nearly $30 \%$ that of water. Therefore, when the PPy actuator is positively biased, TFSI anions along with methanol molecules might more easily penetrate into the porous structure of PPy. Thus, the increased expansion was observed in the LiTFSI electrolyte solutions with $20 \%-50 \%$ of methanol. The TFSI ions diffused into the PPy porous structure in the positive potential region could be disturbed to escape from the PPy structure due to viscosity of the electrolyte solution in the negative potential region. In contrast, the reduced disturbance for the out diffusion of the TFSI anions from the PPy film was expected because the viscosity of the methanol was smaller than that of water. However, the decreased actuating strains of the actuators in the electrolyte solutions containing more than $60 \%$ of methanol after the repeated actuations can not be fully explained by the discussions above.

Higashi et al. recently reported the increase of Young's modulus after repeated actuation in aqueous LiTFSI electrolyte solutions containing $0 \%$ (water), and $20 \%$ of methanol as summarized in Table 2 [29]. Young's modulus increased from 0.13 to $0.45 \mathrm{GPa}$ after 10 cycles of actuations in the electrolyte solution without methanol, and it increased to $4.15 \mathrm{GPa}$ after 10 cycles of actuations in the electrolyte solution containing $20 \%$ of methanol. In addition, notable reduction in the tensile strength and the strains at break of the PPy films actuated in the electrolyte solutions containing methanol were also observed. Although the introduction of methanol in the LiTFSI electrolyte solutions improves the actuating strain of the PPy actuators, the hardening of the PPy actuators after the repeated actuations could be more significant when the concentration of methanol was larger than $60 \%$, which may explain the decreased actuating strains after the repeated actuations in the electrolyte solutions containing methanol more than $60 \%$.

Figure 6(a) shows comparisons of the relationships between the strain and time of the PPy actuators in the LiTFSI electrolyte solution and in the $\mathrm{NaCl}$ electrolyte solution at the potential sweep rate of $200 \mathrm{mV} / \mathrm{s}$ corresponding $0.05 \mathrm{~Hz}$, and Figure 6(b) shows the relationship between the strain and time during electrochemical actuations of PPy actuators in $\mathrm{NaCl}$ electrolyte solutions with different methanol concentrations at the frequency of $0.05 \mathrm{~Hz}$. The PPy actuator in the $\mathrm{NaCl}$ solution clearly caught up with the bias change. Based on these results, the PPy actuators were measured in aqueous solutions of $\mathrm{NaCl}$ with different methanol concentrations of $0 \%, 20 \%$, $40 \%$, and $60 \%$. The electrochemical strain was measured with the frequency of $0.0125,0.025,0.05,0.075$ and 0.1 Hz. The PPy actuator in the solution containing 0\%

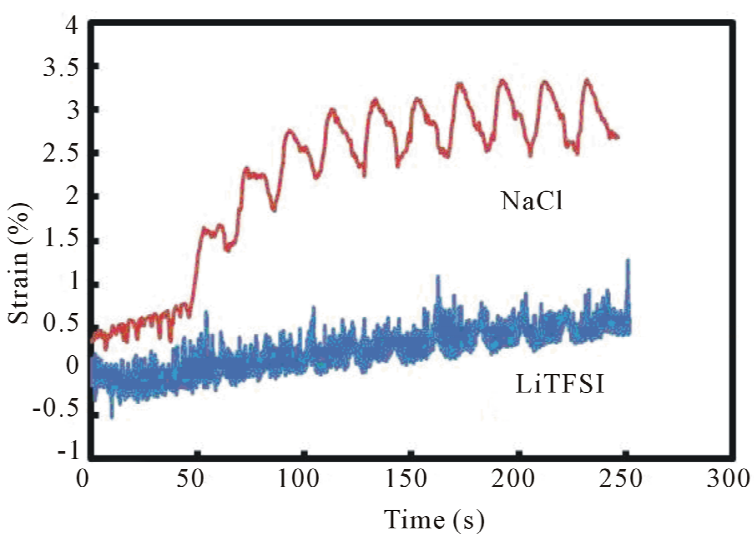

(a)

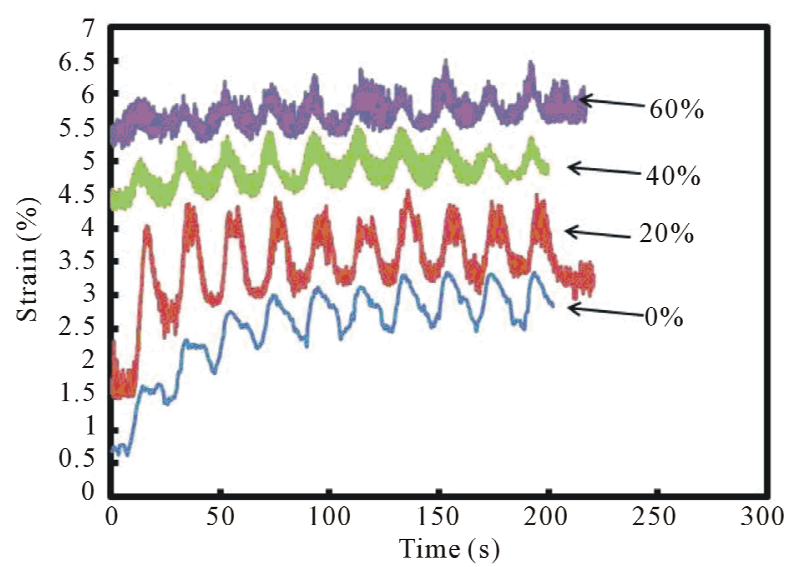

(b)

Figure 6. (a) Comparison of relationships between the strain and time of PPy actuators in LiTFSI electrolyte solution and in $\mathrm{NaCl}$ electrolyte solution at the potential sweep rate of $200 \mathrm{mV} / \mathrm{s}$ corresponding $0.05 \mathrm{~Hz}$, and (b) Relationship between the strain and time during electrochemical actuations of PPy actuators in $\mathrm{NaCl}$ electrolyte solutions with different methanol concentrations at $0.05 \mathrm{~Hz}$. The initial strain was adjusted for better view of the plots.

Table 2. Comparisons of Young's modulus, tensile strength, and tensile strain before and after 10 cycles actuations in the LiTFSI solutions containing $0 \%$ of methanol, and the electrolyte solution containing $20 \%$ of methanol.

\begin{tabular}{cccc}
\hline & $\begin{array}{c}\text { Initial Young's } \\
\text { modulus }(\mathrm{GPa})\end{array}$ & $\begin{array}{c}\text { Tensile } \\
\text { strength }(\mathrm{MPa})\end{array}$ & $\begin{array}{c}\text { Tensile strain } \\
\text { at break }(\%)\end{array}$ \\
\hline $\begin{array}{c}\text { Before } \\
\text { actuation }\end{array}$ & 0.13 & 6.5 & 19 \\
$\begin{array}{c}\text { Aqueous } \\
\text { solution } \\
20 \%\end{array}$ & 0.45 & 6.4 & 6.5 \\
\begin{tabular}{c} 
methanol \\
\hline
\end{tabular} & 4.15 & 3.8 & 4.5 \\
\hline
\end{tabular}

methanol did not function at $0.075 \mathrm{~Hz}$. However, the actuator in the solutions containing $20 \%$, or more methanol functioned at $0.075 \mathrm{~Hz}$. In addition, the PPy actuator in the solutions containing $0 \%$ and $20 \%$ metha- 
nol did not catch up with the $0.1 \mathrm{~Hz}$ actuation. This phenomenon was attributed to the fact that $\mathrm{NaCl}$ was not sufficiently ionized. The actuator caught up with $0.1 \mathrm{~Hz}$ actuation in the solutions containing $40 \%$ and $60 \%$ methanol.

The electrochemical strains of the solutions containing $20 \%$ methanol became the largest. These results attribute this phenomenon to the low viscosity and low surface tension of methanol comparison with the water. Therefore dopant might diffuse into the PPy film smoothly.

Figure 7 shows 1) relationships between the strain and time of the PPy actuators in $\mathrm{NaCl}$ electrolyte solution at the potential sweep rate of $300 \mathrm{mV} / \mathrm{s}$ corresponding $0.075 \mathrm{~Hz}$, and 2) relationships between the strain and time of PPy actuators in $\mathrm{NaCl}$ electrolyte solution at the potential sweep rate of $400 \mathrm{mV} / \mathrm{s}$ corresponding $0.1 \mathrm{~Hz}$. Improvement of the strain was observed by mixing methanol in the $\mathrm{NaCl}$ solution. The actuating strain was increased by mixing $20 \%$ or more of methanol. The actuating strain was the largest by mixing $20 \%$ methanol concentration at $0.075 \mathrm{~Hz}$. On the other hand, the actuating strain was larger for the $\mathrm{NaCl}$ solution containing $40 \%-60 \%$ at $0.1 \mathrm{~Hz}$. Thus, the most suitable $\mathrm{NaCl}$ concentration depends on the actuation frequency. The actuating strain in each methanol concentration at each operating speed was summarized in Table 3.

\section{Summary}

Soft actuators were fabricated using galvanostatic electropolymerization of a PPy thin film using a methyl benzoate electrolyte solution of N,N-Diethyl-N-methyl-N(2-methoxyethyl) ammonium bis (trifluorome-thanesulfonyl) imide. The electrochemical deformation behaviors of the PPy actuator were investigated in aqueous solutions of an electrolyte, LiTFSI $\mathrm{NaCl}$, containing different concentrations of methanol. The actuating strain of approximately $9 \%$ was achieved when the actuator was driven by a potential between -1 and $1 \mathrm{~V}$ with the potential sweep rate of $10 \mathrm{mV} / \mathrm{s}$ corresponding to $0.0025 \mathrm{~Hz}$ in the LiTFSI electrolyte containing $40 \%$ to $50 \%$ of metha-

Table 3. The relationship between the actuation frequency and associated actuating strain.

\begin{tabular}{ccccc}
\hline & \multicolumn{5}{c}{ Methanol concentration (\%) } \\
\cline { 2 - 5 } Frequency $(\mathrm{Hz})$ & 0 & 20 & 40 & 60 \\
\hline 0.0125 & 0.7 & 3.0 & 1.2 & 1.0 \\
0.025 & 0.3 & 1.8 & 1.1 & 1.3 \\
0.05 & 0.8 & 1.5 & 1.0 & 0.8 \\
0.075 & $*$ & 1.1 & 0.5 & 0.5 \\
0.1 & $*$ & $*$ & 0.5 & 0.7 \\
\hline
\end{tabular}

*Actuation strains were under detection limit.

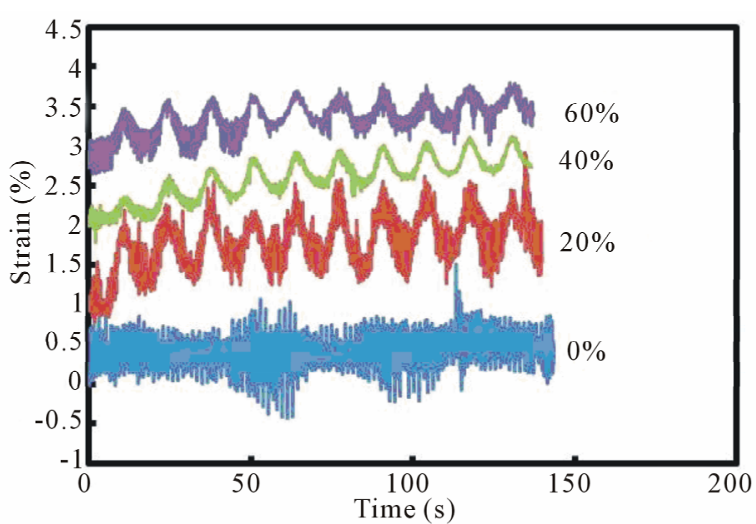

(a)

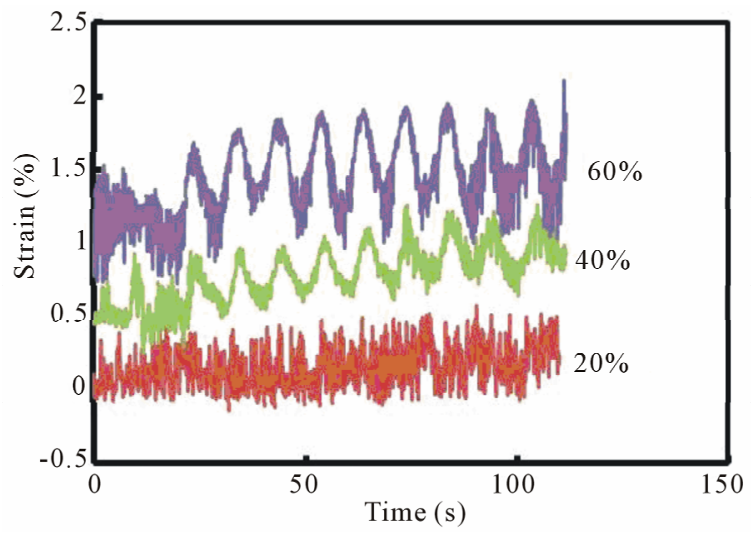

(b)

Figure 7. (a) Relationships between the strain and time of PPy actuators in $\mathrm{NaCl}$ electrolyte solutions at the potential sweep rate of $300 \mathrm{mV} / \mathrm{s}$ corresponding $0.075 \mathrm{~Hz}$, and (b) relationships between the strain and time of PPy actuators in $\mathrm{NaCl}$ electrolyte solution at the potential sweep rate of $400 \mathrm{mV} / \mathrm{s}$ corresponding $0.1 \mathrm{~Hz}$. The initial strain was adjusted for better view of the plots.

nol under a load stress of 0.3 MPa. However, the PPy actuator could not catch up with the higher frequency. On the other hand, the PPy actuator caught up with the potential sweep up to $0.1 \mathrm{~Hz}$ in the $\mathrm{NaCl}$ solutions with a methanol concentration between $40 \%$ and $60 \%$ with the expense of the actuating strain to approximately $1 \%$.

\section{Acknowledgements}

The authors express appreciations to the staffs of the Micro Functional Device Research Center of Nihon University.

\section{REFERENCES}

[1] R. H. Baughman, "Conducting Polymer Artificial Muscles," Synthetic Metals, Vol. 78, No. 3, 1996, pp. 339-353. doi:10.1016/0379-6779(96)80158-5

[2] A. Della Santa, D. De Rossi and A. Mazzoldi, "Performance and Work Capacity of a Polypyrrole Conducting 
Polymer Linear Actuator," Synthetic Metals, Vol. 90, No. 2, 1997, pp. 93-100. doi:10.1016/S0379-6779(97)81256-8

[3] M. Kaneko, M. Fukui, W. Takashima and K. Kaneto, "Electrolyte and Strain Dependences of Chemomechanical Deformation of Polyaniline Film," Synthetic Metals, Vol. 84, No. 1-3, 1997, pp. 795-796. doi:10.1016/S0379-6779(96)04150-1

[4] J. D. Madden, R. A. Cush, T. S. Kanigan, C. J. Brenan and I. W. Hunter, "Encapsulated Polypyrrole Actuators," Synthetic Metals, Vol. 105, No. 1, 1999, pp. 61-64. doi:10.1016/S0379-6779(99)00034-X

[5] A. S. Hutchison, T. W. Lewis, S. E. Moulton, G. M. Spinks and G. G. Wallace, "Development of PolypyrroleBased Electromechanical Actuators," Synthetic Metals, Vol. 113, No. 1-2, 2000, pp. 121-127. doi:10.1016/S0379-6779(00)00190-9

[6] T. Morita, Y. Chida, D. Hoshino, T. Fujiya and Y. Nishioka, "Fabrication and Characterization of a Polypyrrole Soft Actuator Having Corrugated Structures," Molecular Crystals and Liquid Crystals, Vol. 519, No. 1, 2010, pp. 121-127. doi:10.1080/15421401003609681

[7] Y. Chida, H. Katsumata, T. Fujiya, S. Kaihatsu, T. Morita, D. Hoshino and Y. Nishioka, "Silicon Linear Actuator Driven by Electrochemomechanical Strain of Polypyrrole Film," Sensors and Actuators A: Physical, Vol. 169, No. 2, 2011, pp. 367-372. doi:10.1016/j.sna.2010.12.009

[8] Y. Nishioka, "Polypyrrole Soft Actuators," In: E. SchabBalcerzak, Ed., Electropolymerization, Intech, Rijeka, 2011, pp. 159-186. doi:10.5772/28329

[9] K. Kaneto, Y. Sonoda and W. Takashima, "Direct Measurement and Mechanism of Electro-Chemomechanical Expansion and Contraction in Polypyrrole Films," Japanese Journal of Applied Physics, Vol. 39, No. 10, 2000, pp. 5918-5922. doi:10.1143/JJAP.39.5918

[10] L. Bay, K. West, P. Sommer-Larsen, S. Skaarup and M. Benslimane: "A Conducting Polymer Artificial Muscle with 12\% Linear Strain," Advanced Materials, Vol. 15, No. 4, 2003, pp. 310-313. doi:10.1002/adma.200390075

[11] S. Hara, T. Zama, W. Takashima and K. Kaneto, "Artificial Muscles Based on Polypyrrole Actuators with Large Strain and Stress Induced Electrically," Polymer Journal, Vol. 36, No. 2, 2004, pp. 151-161. doi:10.1295/polymi.36.151

[12] T. Zama, S. Hara, W. Takashima and K. Kaneto, "The Correlation between Electrically Induced Stress and Mechanical Tensile Strength of Polypyrrole Actuator," Bulletin of the Chemical Society of Japan, Vol. 77, 2004, pp. 1425-1426. doi:10.1246/bcsj.77.1425

[13] S. Hara, T. Zama, W. Takashima and K. Kaneto, "TFSIDoped Polypyrrole Actuator with 26\% Strain," Journal of Materials Chemistry, Vol. 14, No. 10, 2004, pp. 15161517. doi: $10.1039 / \mathrm{b} 404232 \mathrm{~h}$

[14] S. Hara, T. Zama, W. Takashima and K. Kaneto: "GelLike Polypyrrole Based Artificial Muscles with Extremely Large Strain," Polymer Journal, Vol. 36, 2004, pp. 933-936. doi:10.1295/polymj.36.933

[15] M. J. M. Jafeen, M. A. Careem and S. Skaarup, "Speed and Strain of Polypyrrole Actuators: Dependence on
Cation Hydration Number," Ionics, Vol. 16, No. 1, 2010 , pp. 1-6. doi:10.1007/s11581-009-0393-6

[16] K. Yamato and K. Kaneto, "Tubular Linear Actuators Using Conducting Polymer, Polypyrrole," Analytica Chimica Acta, Vol. 568, No. 1-2, 2006, pp. 133-137. doi:10.1016/j.aca.2005.12.030

[17] T. Sendai, H. Suematsu and K. Kaneto, "Anisotropic Strain and Memory Effect in Electrochemomechanical Strain of Polypyrrole Films under High Tensile Stresses," Japanese Journal of Applied Physics, Vol. 48, No. 5, 2009, Article ID: 051506. doi:10.1143/JJAP.48.051506

[18] W. Takashima, S. S. Pandey and K. Kaneto, "Cyclic Voltammetric and Electrochemomechanical Characteristics of Freestanding Polypyrrole Films in Diluted Media," Thin Solid Films, Vol. 438-439, 2003, pp. 339-345. doi:10.1016/S0040-6090(03)00757-0

[19] W. Takashima, S. S. Pandey and K. Kaneto: "Investigation of Bi-Ionic Contribution for the Enhancement of Bending Actuation in Polypyrrole Film," Sensors and Actuator B, Vol. 89, No. 1-2, 2003, pp. 48-52. doi:10.1016/S0925-4005(02)00426-4

[20] J. D. Madden, R. A. Cush, T. S. Kanigan and I. W. Hunter, "Fast Contracting Polypyrrole Actuators," Synthetic Metals, Vol. 113, No. 1-2, 2000, pp. 185-192. doi:10.1016/S0379-6779(00)00195-8

[21] Y. Wu, G. Alici, G. M. Spinks and G. G. Wallace, "Fast Trilayer Polypyrrole Bending Actuators for High Speed Applications," Synthetic Metals, Vol. 156, No. 16-17, 2006, pp. 1017-1022. doi:10.1016/j.synthmet.2006.06.022

[22] G. M. Spinks, T. E Campbell and G. G. Wallace, "Force Generation from Polypyrrole Actuators," Smart Materials and Structures, Vol. 14, No. 2, 2005, pp. 406-412. doi:10.1088/0964-1726/14/2/015

[23] J. D. W. Madden, P. G. A. Madden and I. W. Hunter, "Conducting Polymer Actuators as Engineering Materials," Proceedings of SPIE, Vol. 4695, 2002, p. 176. doi: $10.1117 / 12.475163$

[24] S. Skaarup, L. Bay and K. West, "Polypyrrole Actuators Working at 2 - $30 \mathrm{~Hz}$," Synthetic Metals, Vol. 157, No. 6-7, 2007, pp. 323-326. doi:10.1016/j.synthmet.2007.04.001

[25] S. Hara, T. Zama, W. Takashima and K. Kaneto, "FreeStanding Polypyrrole Actuators with Response Rate of $10.8 \% \mathrm{~s}^{-1}$," Synthetic Metals, Vol. 149, No. 2-3, 2005, pp. 199-201. doi:10.1016/j.synthmet.2005.01.003

[26] D. Hoshino, T. Morita, Y. Chida, Z. Duan, S. Ogihara, Y. Suzuki and Y. Nishioka, "Effect of 2-Propanol Concentration in Electrolyte Solution on Polypyrrole Actuator Performance," Japanese Journal of Applied Physics, Vol. 50, No. 1, 2011, 01BG10. doi:10.1143/JJAP.50.01BG10

[27] F. Tsumuji, D. Hoshino, S. Ogihara, Z. Duan, Y. Suzuki, T. Kadoyama, J. Yamasaki and Y. Nishioka, "Polypyrrole Actuator Operating Characteristics in Electrolyte Solution Mixed with Methanol," Journal of Applied Mathematics and Mechanics, Vol. 300-301, 2013, pp. 1352-1355. doi:10.4028/www.scientific.net/AMM.300-301.1352

[28] Y. Chida, T. Morita, R. Machida, D. Hoshino and Y. 
Nishioka, "Fabrication of Bi-Directional Bending Organic Actuators Consisting of Stacked Polypyrrole Films with Different Expansion and Contraction Ratios," Molecular Crystals and Liquid Crystals, Vol. 519, No. 1, 2010, pp. 115-120. doi:10.1080/15421401003609475

[29] M. Higashi, D. Hoshino, Z. Duan, S. Ogihara, Y. Suzuki,
F. Tsumuji, H. Obayashi and Y. Nishioka, "Influence of Electrochemical Actuations on Mechanical Properties of PPy Actuators in Electrolyte Solutions Mixed with 2-Propanol or Methanol," Molecular Crystals and Liquid Crystals, Vol. 566, No. 1, 2012, pp. 1-5. doi:10.1080/15421406.2012.701886 